\title{
Pregnancy outcomes and outdoor air pollution: an ecological study in districts of the Czech Republic 1986-8
}

\author{
Martin Bobak, David A Leon
}

\begin{abstract}
Objectives-Outdoor air pollution has consistently been shown to predict mortality. The finding that this association is stronger in infants than in children or adults raises the question whether air pollution could also be related to pregnancy outcomes-such as birthweight and stillbirth. The association between outdoor air pollution and stillbirths and low birthweight in the Czech Republic, where air pollution was high, was examined.

Methods-An ecological study was conducted, with routinely collected data on stillbirths and low birthweight $(<2500 \mathrm{~g})$, air pollution (total suspended particulates, sulphur dioxide $\left(\mathrm{SO}_{2}\right)$, and nitrogen oxides $\left(\mathrm{NO}_{\mathrm{x}}\right)$ ), and socioeconomic factors (mean income, car ownership, divorce rate, etc). The analyses were restricted to 45 districts on which data on air pollution were available for the period 1986-8. The effects of exposure variables on frequency of pregnancy outcomes were estimated by logistic regression with district-years as the units of analysis.
\end{abstract}

Results-Stillbirth rate $(4.2 / 1000$ births in monitored districts) was not significantly associated with any indicator of air pollution, and was weakly related to mean income and proportion of births outside marriage. Crude prevalence of low birthweight (prevalence 5.5\%) showed highly significant associations with several socioeconomic factors; after controlling for these, odds ratios (ORs) I $50 \mu \mathrm{g} / \mathrm{m}^{3}$ increase in pollutant were: 1.04 (95\% confidence interval (95\% CI) 0.96 to 1.12$)$ for total suspended particles, 1.10 (1.02 to 1.17) for $\mathrm{SO}_{2}$, and $1.07(0.98$ to 1.16$)$ for $\mathrm{NO}_{\mathrm{x}}$. When all pollutants were included in one model, $\mathrm{SO}_{2}$ remained related to low birthweight (OR 1.10 (1.01 to 1.20),

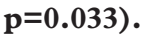

Conclusion-These results are consistent with a recent study in China where birthweight was also associated with total suspended particles and $\mathrm{SO}_{2}$ but ecological studies must be interpreted cautiously. Residual confounding by socioeconomic factors cannot be ruled out. The association between air pollution and birthweight requires further investigation. (Occup Environ Med 1999;56:539-543)

Keywords: air pollution; pregnancy; birthweight; stillbirth; socioeconomic factors; epidemiology
Ambient air pollution has been repeatedly shown to be strongly associated with mortality in both time series ${ }^{1-3}$ and cross sectional studies ${ }^{4-6}$ with particulates being most consistently linked with adverse health effects. ${ }^{7}$ The finding of strong effects of air pollution in infancy ${ }^{6-8}$ raises the question whether pollution could also influence birthweight or other pregnancy outcomes.

Although such effects have been suspected, ${ }^{9}$ only a few published reports have examined this issue. A British study did not find an increased prevalence of low birthweight near a source of air pollution. ${ }^{10}$ By contrast, a recent study in Beijing, China, found that concentrations of particulates and sulphur dioxide $\left(\mathrm{SO}_{2}\right)$ during the third trimester of pregnancy were associated with birthweight, after controlling for season and individually measured covariates. ${ }^{11}$ Most recently, a careful comparison of two Czech districts found that exposure to high levels of air pollution in the first trimester of pregnancy were related to higher risk of low birthweight. ${ }^{11 \mathrm{~A}}$

There are two main problems with accepting these associations as potentially causal. Firstly, it is not known how consistent is the association between air pollution and birthweight across different populations and datasets. Secondly, the biological mechanisms for such an association are not clear. In this report, we have considered the first issue. We have previously used data on air pollution and births collected routinely in districts of the Czech Republic in 1986-8 to study infant mortality. ${ }^{6}$ Prompted by the recent reports about birthweight, we have reanalysed these data to examine the possible association between air pollution and two pregnancy outcomes: low birthweight and stillbirths.

\section{Methods}

This ecological study analysed data from 45 of the 85 administrative districts of the Czech Republic where air pollution was monitored by the National Public Health Service 1986-8. ${ }^{6}$ Most districts had at least three monitoring stations, most of them were in the principle towns of the districts. The monitoring stations provided daily averages of total suspended particulates, sulphur dioxide $\left(\mathrm{SO}_{2}\right)$, and the sum of oxides of nitrogen $\left(\mathrm{NO}_{\mathrm{x}}\right)$. Uniform methods of measurement were used in all districts: total suspended particles were measured by the gravimetric method, and $\mathrm{SO}_{2}$ and $\mathrm{NO}_{\mathrm{x}}$ by spectrophotometry. In the period covered by this study, public health services in the Czech 
Table 1 Descriptive data on districts included in the analyses

\begin{tabular}{|c|c|c|c|c|c|c|}
\hline & \multirow{2}{*}{$\begin{array}{l}\text { Whole Czech } \\
\text { Republic }\end{array}$} & \multicolumn{5}{|c|}{ Selected 45 districts with data on air quality } \\
\hline & & Mean & Min & $\operatorname{Max}$ & $25 \%$ & $75 \%$ \\
\hline \multicolumn{7}{|l|}{ Pregnancy outcomes: } \\
\hline Low birth weight $(<2500 \mathrm{~g}, \%)$ & 5.5 & 5.9 & 3.6 & 9.1 & 5.1 & 6.7 \\
\hline Stillbirths (/ 1000 total births) & 4.18 & 4.23 & 0 & 9.98 & 2.84 & 5.98 \\
\hline \multicolumn{7}{|c|}{ Annual geometrical means of air pollutants: } \\
\hline Suspended particulates $\left(\mu \mathrm{g} / \mathrm{m}^{3}\right)$ & - & 68.5 & 33.5 & 115.5 & 57.5 & 79.0 \\
\hline Sulphur dioxide $\left(\mu \mathrm{g} / \mathrm{m}^{3}\right)$ & - & 31.9 & 4.4 & 107.4 & 13.9 & 52.8 \\
\hline Nitrogen oxides $\left(\mu \mathrm{g} / \mathrm{m}^{3}\right)$ & - & 35.1 & 6.1 & 88.2 & 19.1 & 52.2 \\
\hline \multicolumn{7}{|l|}{ Socioeconomic characteristics: } \\
\hline Births outside marriage (\%) & 6.9 & 9 & 1 & 21 & 5 & 12 \\
\hline Abortions / 100 births & 77.5 & 80.7 & 35.5 & 115.4 & 68.9 & 94.3 \\
\hline Divorces / 100 marriages & 0.37 & 0.39 & 0.18 & 0.61 & 0.32 & 0.45 \\
\hline Mean income (Czech Crowns) & 2423 & 2537 & 2323 & 2994 & 2412 & 2646 \\
\hline Mean savings (Czech Crowns) & 10168 & 9837 & 4851 & 14649 & 7077 & 11766 \\
\hline People / car (mean) & 7.2 & 6.9 & 4.8 & 11.4 & 5.4 & 8.1 \\
\hline
\end{tabular}

Republic were strictly centralised. All public health centres were equipped with the same technology, and analytical methods were specified by national guidelines. Also, national and regional authorities often conducted inspections in districts to insure that standard methods were used.

It has been estimated that particles with a diameter $<10 \mu \mathrm{m}\left(\mathrm{PM}_{10}\right)$ constitute about $80 \%$ of the total suspended particles measured in the Czech Republic (Kotlik, Czech National Institute of Public Health, personal communication). For the study period, data were

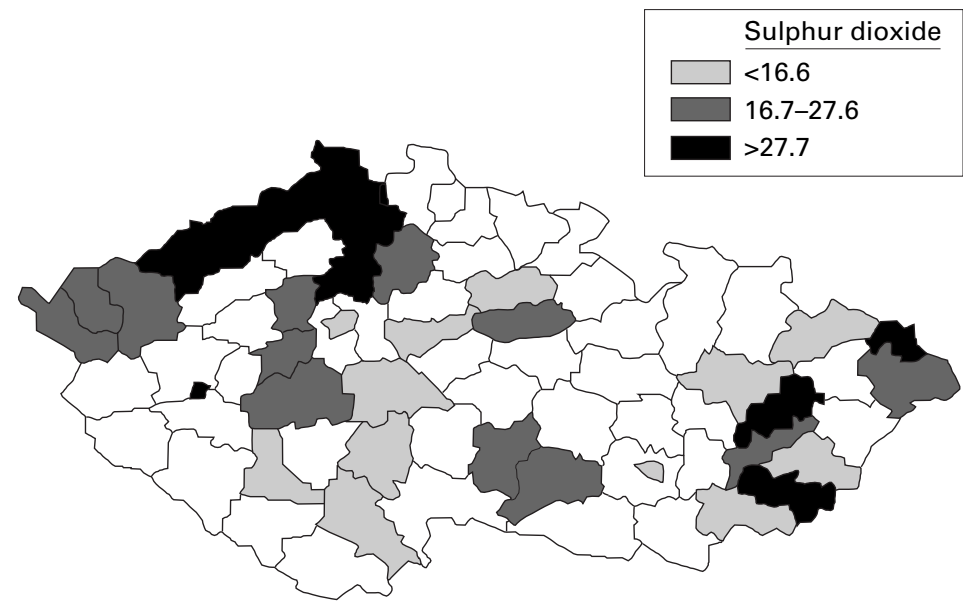

Figure 1 Annual geometric means of $\mathrm{SO}_{2}$ concentrations in Czech districts in 1987. (No data available for unshaded areas.)

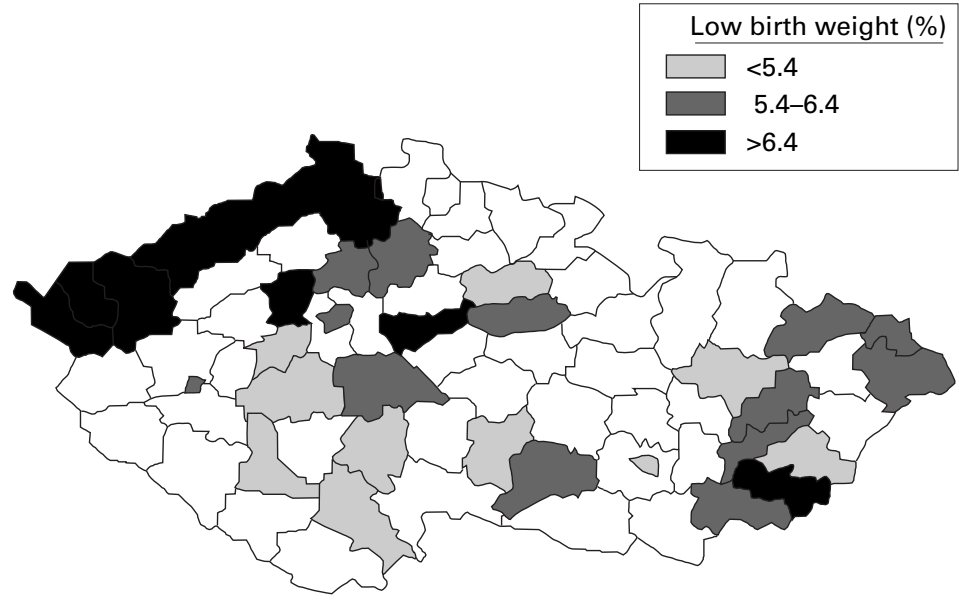

Figure 2 Prevalence of low birthweight $(<2500 \mathrm{~g})$ in Czech districts for which data on air pollution were available in 1987. (No data on air pollution for unshaded districts.) available only in the form of annual arithmetic or geometric means of all daily readings in all stations in a given district in each year. Annual geometric means were used as the independent variable in the present analyses. The number of monitored districts increased during the study period (37 in 1986, 39 in 1987, and 45 in 1988), resulting in 121 units for analysis with data on all three pollutants.

Data on pregnancy outcomes were taken from routine registration of births published (in printed form) by the Czech Statistical Office. Registration of births is required by law in the Czech Republic. The registration form, which includes information on birthweight and stillbirths, was completed by the physician attending the delivery, and sent to the Czech Statistical Office. The Czech Statistical Office then published data aggregated by district. Low birthweight was defined as birthweight $<2500 \mathrm{~g}$, and stillbirth was defined as the birth of a dead infant weighing $>1000 \mathrm{~g}$ or of $\geqslant 28$ weeks of gestation. Although the birth registration data have not been formally validated, they are considered to be complete and accurate.

For each district, the annual prevalence of low birthweight and stillbirths was calculated. The association between air pollution and frequency of pregnancy outcomes was estimated in logistic regression on grouped data with the STATA statistical package. ${ }^{12}$ The unit of analysis was the annual experience of each district. The effects of air pollutants were analysed in three stages. Firstly, crude effects were estimated by including each pollutant separately in the model. Secondly, each pollutant was adjusted for several socioeconomic characteristics of the districts obtained from the Czech Statistical Office; these factors were mean income, mean savings, mean number of people / car, proportions of births outside marriage, proportion of divorces to new marriages, legally induced abortions / 100 live births, and proportion of gypsies in the population. Finally, all three pollutants were included in one model with socioeconomic factors (see fully adjusted models in tables 2 and 3). The effects are expressed as odds ratios (ORs) associated with an increase in pollutant concentration of $50 \mu \mathrm{g} / \mathrm{m}^{3}$. For the socioeconomic variables, ORs are given for the change between 25th and 75th percentile, because 
Table 2 Odds ratios for low birth weight $(<2500 \mathrm{~g}) / 50 \mu \mathrm{g} / \mathrm{m}^{3}$ increase in air pollutants and for change from $25 \mathrm{th}$ to $75 \mathrm{th}$ percentile of socioeconomic variables

\begin{tabular}{llll}
\hline & Crude & $\begin{array}{l}\text { Adjusted for } \\
\text { socioeconomic factors }\end{array}$ & Fully adjusted \\
\hline Suspended particulates & $1.06(0.97-1.17)$ & $1.04(0.96-1.12)$ & $1.03(0.95-1.11)$ \\
Sulphur dioxide & $1.21(1.13-1.30)^{\star \star \star}$ & $1.10(1.02-1.17)^{\star \star}$ & $1.10(1.01-1.20)^{\star}$ \\
Nitrogen oxides & $1.14(1.04-1.24)^{\star \star}$ & $1.07(0.98-1.16)$ & $0.99(0.89-1.10)$ \\
Births outside marriage (\%) & $1.17(1.14-1.21)^{\star \star \star}$ & $1.09(1.03-1.16)^{\star \star}$ & $1.08(1.01-1.14)^{\star}$ \\
Abortions / 100 births & $1.01(0.96-1.06)$ & $0.98(0.94-1.03)$ & $0.98(0.94-1.02)$ \\
Divorces / 100 marriages & $1.08(1.03-1.13)^{\star \star}$ & $1.04(0.97-1.11)$ & $1.02(0.95-1.09)$ \\
Mean income (Czech Crowns) & $1.03(0.98-1.07)$ & $0.99(0.96-1.03)$ & $0.99(0.95-1.03)$ \\
Mean savings (Czech Crowns) & $0.84(0.80-0.88)$ & $0.85(0.79-0.91)^{\star \star \star}$ & $0.85(0.79-0.92)^{\star \star \star}$ \\
People / car (mean) & $1.04(0.98-1.10)$ & $0.94(0.88-1.00)^{\star}$ & $0.93(0.88-0.99)^{\star}$ \\
$\mathrm{R}^{2}$ for model with pollutants & $0.01-0.19\left(\mathrm{SO}_{2}\right)$ & $0.50-0.52\left(\mathrm{SO}_{2}\right)^{\star}$ & 0.52 \\
\hline
\end{tabular}

${ }^{\star} \mathrm{p}<0.05 ;{ }^{\star \star} \mathrm{p}<0.01 ;{ }^{\star \star \star} \mathrm{p}<0.001$.

$\mathrm{R}^{2}=0.50$ for socioeconomic factors only.

Table 3 Odds ratios for stillbirths $/ 50 \mu \mathrm{g} / \mathrm{m}^{3}$ increase in air pollutants and for change from 25th to 75th percentile of socioeconomic variables

\begin{tabular}{llll}
\hline & Crude & $\begin{array}{l}\text { Adjusted for socioeconomic } \\
\text { factors }\end{array}$ & Fully adjusted \\
\hline Suspended particulates & $0.94(0.77-1.14)$ & $0.96(0.77-1.18)$ & $0.92(0.74-1.15)$ \\
Sulphur dioxide & $1.07(0.91-1.26)$ & $0.98(0.80-1.20)$ & $0.90(0.70-1.16)$ \\
Nitrogen oxides & $1.07(0.89-1.29)$ & $1.10(0.86-1.39)$ & $1.21(0.89-1.64)$ \\
Births outside marriage (\%) & $1.10(1.01-1.21)^{\star}$ & $0.95(0.80-1.14)$ & $0.94(0.78-1.12)$ \\
Abortions / 100 births & $0.98(0.90-1.13)$ & $0.93(0.82-1.06)$ & $0.92(0.81-1.05)$ \\
Divorces / 100 marriages & $1.05(0.96-1.16)$ & $1.15(0.95-1.40)$ & $1.14(0.92-1.40)$ \\
Mean income (Czech Crowns) & $0.97(0.89-1.05)$ & $0.94(0.85-1.05)$ & $0.94(0.85-1.04)$ \\
Mean savings (Czech Crowns) & $0.87(0.78-0.98)^{\star}$ & $0.79(0.64-0.97)^{\star}$ & $0.75(0.61-0.94)^{\star}$ \\
People / car (mean) & $1.01(0.90-1.13)$ & $0.93(0.78-1.10)$ & $0.90(0.76-1.08)$ \\
$\mathrm{R}^{2}$ for model with pollutants & 0.01 & 0.05 & 0.04 \\
\hline
\end{tabular}

${ }^{\star} \mathrm{p}<0.05 ;{ }^{\star \star} \mathrm{p}<0.01 ;{ }^{\star \star \star} \mathrm{p}<0.001$.

$\mathrm{R}^{2}=0.05$ for socioeconomic factors only.

these factors are expressed in different units. For each stage of the analysis, the proportion of the variation among units of analysis explained by the independent variables (approximation of $R^{2}$ ) is also given.

\section{Results}

There were almost 400000 births in the Czech Republic in 1986-8, 223929 of them in monitored districts; of these, 971 were stillbirths. The prevalence of low birthweight in the whole country and in monitored districts was $5.5 \%$ and $5.9 \%$, respectively; stillbirth rates were 4.18 and $4.23 / 1000$ total births, respectively (table 1). The population size of the districts varied between 48108 and 387078 (mean 145 410); accordingly, annual number of births varied between 442 and 4622 (mean 1851). The annual means of total suspended particles, $\mathrm{SO}_{2}$, and $\mathrm{NO}_{x}$ in the monitored districts were 69,32 , and $35 \mu \mathrm{g} / \mathrm{m}^{3}$, respectively. Differences in exposure among districts were relatively large, particularly for $\mathrm{SO}_{2}$ and $\mathrm{NO}_{\mathrm{x}}$. Apart from higher proportion of births outside marriage, the socioeconomic profile of monitored districts was similar to that in the whole country.

Figures 1 and 2 show the spatial distribution of annual means of $\mathrm{SO}_{2}$ and the prevalence of low birthweight in the districts included in the analyses (where data on pollution were available). Although the overlap is not perfect, both pollution and prevalence of low birthweight were higher in the north western districts.

Statistically, the prevalence of low birthweight was positively associated with concentrations of two air pollutants in crude analyses (table 2). Odds ratios $/ 50 \mu \mathrm{g} / \mathrm{m}^{3}$ increase in $\mathrm{SO}_{2}$ and $\mathrm{NO}_{\mathrm{x}}$ were 1.21 (95\% confidence interval (95\% CI) 1.13 to 1.30 ) and 1.14 (1.04 to
1.24), respectively. Adjustment for the socioeconomic characteristics of the districts reduced these estimates by about a half, and only $\mathrm{SO}_{2}$ retained its significance $(\mathrm{p}=0.010)$. Adjusted ORs for quintiles of districts (mean $\mathrm{SO}_{2}$ concentrations $9.3,16.5,28.4,44.8$, and 60.7 $\mu \mathrm{g} / \mathrm{m}^{3}$ ) were $1.00,0.99,1.03,1.06$, and 1.12 , respectively; this is consistent with the effects estimated with $\mathrm{SO}_{2}$ as a continuous variable. Full adjustment, with all pollutants and socioeconomic factors in one model, did not reduce the OR of $\mathrm{SO}_{2}(\mathrm{p}=0.033)$ but removed entirely any effect of $\mathrm{NO}_{\mathrm{x}}$. Socioeconomic factors contributed substantially to explaining the variation among the districts; $R^{2}$ was 0.50 for the model with socioeconomic variables only; inclusion of $\mathrm{SO}_{2}$ increased the $R^{2}$ by only 0.02 .

Table 3 shows the effects of air pollution on stillbirths. None of the pollutants showed a significant association with the prevalence of stillbirths. Among the socioeconomic factors, only mean savings and proportion of births outside marriage showed marginally significant relations. The overall proportion of geographical variation explained by the full model was $<5 \%$.

\section{Discussion}

In this ecological study, stillbirths were not significantly related to air pollution and only marginally significantly to mean savings and birth outside marriage. Prevalence of low birthweight, on the other hand, was positively associated with $\mathrm{SO}_{2}$, and was strongly related to socioeconomic characteristics of the districts.

This study covers the years $1986-8$ when the Czech Republic had some of the highest levels of air pollution in Europe. ${ }^{13}$ Two thirds of the monitored districts recorded annual mean concentrations of suspended particulate matter above the World Health Organisation 
guidelines. ${ }^{14}$ High levels of air pollution and large geographical variation in concentrations in the Czech Republic at that time increase the power of a study to show the effects of air pollution on health. The selection of the 45 monitored districts may restrict somewhat the ability of these findings to be generalised for the whole country but should not affect the internal validity of the study.

Apart from the well known limitations of ecological studies, ${ }^{15}$ several other limitations of these analyses need to be considered. The units of analysis in this study were not independent; depending on the number of years for which pollution data were available, each district was included up to three times in the dataset. This could lead to serial autocorrelation. Moreover, neighbouring districts may be more similar to each other for both pollution and birth outcomes, which would suggest spatial autocorrelation. ${ }^{16}$ We have not conducted formal tests for autocorrelation. However, although autocorrelation would lead to underestimation of random error (and thus the widths of the $95 \%$ CIs), it does not affect the point estimates of the ORs.

Although autocorrelation would tend to overestimate the significance of the ORs, random misclassification of exposure would have the opposite effects. ${ }^{17}$ The use of district means misclassified the exposures of individual people for several reasons. Firstly, it reduced the spatial variation in exposure within districts to an overall mean. Secondly, it flattened the seasonal variation. And thirdly, annual data lead to assigning incorrect exposure to births which occurred at the beginning of each year. For example, a women giving birth in January would be assigned concentrations of pollution which prevailed after the birth. All these types of misclassification are most likely to be random, and would lead to underestimation of the effects of air pollution. In our view, exposure misclassification in this study biased the effects of air pollution towards unity.

Misclassification of socioeconomic factors, important potential confounders, may be a potential problem, although many different indicators were used to remove their effects. The indicators used in this study characterise different aspects of the socioeconomic environment. Divorce rate, abortions, and births outside marriage are related to traditional values and social stability. Mean savings (there was only one state owned bank before 1990), mean income (all companies were owned by the state, and the state paid all salaries), and car ownership, on the other hand, reflect the economic conditions.

In bivariate correlations, air pollution was related to most socioeconomic characteristics. Socioeconomic factors are strongly associated with low birthweight, and including socioeconomic characteristics in the model roughly halved the effects of $\mathrm{SO}_{2}$ on risk of low birthweight. If socioeconomic factors were misclassified, their effects would be underestimated, and this could result in residual confounding. ${ }^{18}$ As well as regression modelling, we have used an alternative way to assess this possibility. Infant mortality from external causes, known to be strongly related to socioeconomic status, was regressed against air pollution. The fact that no association was found (not shown) does not support the existence of residual confounding by socioeconomic factors. Similarly, in the presented analyses, the effects of $\mathrm{SO}_{2}$ were only found for low birthweight but not for stillbirth, although stillbirth has also been linked to socioeconomic status in some ${ }^{19}{ }^{20}$ (but not all ${ }^{21}$ ) populations. Socioeconomic factors most likely capture the well known effects of maternal smoking on birthweight ${ }^{22}$; it is unlikely that maternal smoking is associated with air pollution independently from socioeconomic status. However, there may be other, unmeasured, characteristics of the districts, and our findings must be interpreted cautiously and require independent confirmation.

Smith and Lee suggested that some effects of air pollution on pregnancy outcome would be intuitively expected, perhaps mediated by more respiratory morbidity during pregnancy. ${ }^{9}$ Surprisingly few published studies considered this question. A British study comparing the population living around a point source of air pollution with a control population did not find any increase in prevalence of low birthweight in the polluted area. ${ }^{10}$ The Chinese study, with individual data on confounders and place of residence to assign exposure, found a linear association between air pollution and low birthweight; with ORs of 1.11 (95\% 1.06 to 1.16 ) and 1.10 (95\% CI 1.05 to 1.14$) / 100$ $\mu \mathrm{g} / \mathrm{m}^{3}$ of total suspended particles and $\mathrm{SO}_{2}$, respectively. Our results, expressed / $100 \mu \mathrm{g} / \mathrm{m}^{3}$, were 1.08 and 1.21 , respectively, after controlling for socioeconomic factors. For $\mathrm{SO}_{2}$, the effects found in our data are much stronger.

The recent results of the Czech and United States Environmental Protection Agency research project, which collected individual data on mothers and babies in two areas of the Czech Republic, suggested that women exposed to high concentrations of particulates $\left(>50 \mu \mathrm{g} / \mathrm{m}^{3}\right)$, compared with those exposed to low concentrations $\left(\leqslant 40 \mu \mathrm{g} / \mathrm{m}^{3}\right)$ during the first trimester, had a greater risk of giving birth to a baby with birthweight below the 10 th percentile of birthweight for gestational age and sex (OR 2.64, 95\% CI 1.48 to $4.71 .^{11 \mathrm{~A}}$ In their study, the critical exposure period seemed to be the first month of pregnancy. As socioeconomic factors (and maternal smoking) were carefully controlled for, these results do not seem to be due to confounding.

Interpretation of epidemiological studies reporting an association between air pollution and birthweight needs caution. Although a range of social and behavioural determinants of birthweight or preterm birth have been identified, the biological mechanisms leading to prematurity are not well understood, ${ }^{23}$ and it is not clear which mechanisms could provide the link between air pollution and birthweight. Infection in pregnancy is a predictor of premature births, ${ }^{24}$ and it could be speculated that repeated infections, possibly related to pollution, might play a part. Increased blood viscos- 
ity, found during air pollution episodes, ${ }^{25}$ may be related to impaired placental function. ${ }^{26}$ Increased concentrations of DNA adducts have been found in blood ${ }^{27}{ }^{28}$ and placentas ${ }^{29}$ of subjects living in polluted areas, and were also found to be related to birthweight. ${ }^{30}$

Although elucidating the biological pathways is important, the association needs to be well established first. Replication of the findings in different populations and datasets is a part of this process. The association has now been found in three independent datasets but this hypothesis requires further testing, and existing data from other populations can do this. If these findings are confirmed, they would provide an important contribution to the debate on reducing the exposures to air pollution world wide.

1 Schwartz J, Marcus A. Mortality and air pollution in London: a time series analysis. Am $\mathscr{f}$ Epidemiol 1990;131:185-94.

2 Touloumi G, Pocock SJ, Katsouyanni K, et al. Short-term effects of air pollution on daily mortaity in Athens: a timeseries analysis. Int $\mathcal{F}$ Epidemiol 1994;23:957-67.

3 Health Effects Institute. Particulate air pollution and daily mortality. Replication and validation of selected studies. The phase I report of the particle epidemiology evaluation project. Cambridge, MA: Health Effects Institute, 1995.

4 Evans JS, Tosteson T, Kinney PL. Cross-sectional mortality and air pollution risk assessment. Environ Int 1984;10:5383.

5 Lave LB, Seskin EP. Air pollution and human health. Baltimore: John Hopkins University Press, 1977.

6 Bobak M, Leon DA. Air pollution and infant mortality in the Czech Republic, 1986-88. Lancet 1992;340:1010-14.

7 Dockery DW, Pope III CA. Acute respiratory effects of particulate air pollution. Ann Rev Public Health 1994:15:10732 .

8 Saldiva PHN, Lichtenfels AJFC, Paiva PSO, et al. Association between air pollution and mortality due to respiratory diseases in children in Sao Paulo, Brazil: a preliminary report. Environ Res 1994;65:218-25.

9 Smith KR, Lee Y-SF. Urbanization and the environmental risk transition. In: Kasarda JD, Parnell AM, eds. Third world cities. Problems, policies, and prospects. London: Sage, 1992:161-82.

10 Bhopal RS, Phillimore P, Moffatt S, et al. Is living near a coking works harmful to health? A study of industrial air pollution. F Epidemiol Community Health 1994;48:237-47.

11 Wang X, Ding H, Ryan L, et al. Association between air pollution and low birthweight: a community based study. Environ Health Perspect 1997;105:514-20.
11A Dejmek J, Selevan SG, Benes I, et al. Fetal growth and maternal exposure to particulate matter during pregnancy. Environ Health Perspect 1999 (in press).

12 StataCorporation. Stata statistical software: release 4.0. College Station, TX: Stata, 1995.

13 Ministry of Environment of the Czech Republic. Zivotni prostredi Ceske republiky. (Environment in the Czech Republic). Prague: Academia, 1990.

14 World Health Organization . Air quality guidelines for Europe. Copenhagen: WHO Regional Office for Europe, 1987.

15 Piantadosi S, Byar DP, Green SB. The ecological fallacy. Am 7 Epidemiol 1988;127:893-904.

16 Cliff AD, Haggett P. Atlas of disease distributions. Analytical approaches to epidemiological data. Oxford: Blackwell, 1988.

17 Kleinbaum DG, Kupper LL, Morgenstern H. Epidemiologic research. Principles and quantitative methods. New York: Van Nostrand Reinhold, 1982.

18 Phillips AN, Davey Smith G. How independent are "independent" effects? Relative risk estimation when correlated exposures are measured imprecisely. $\mathcal{F}$ Clin Epidemiol 1991;44:1223-31.

19 Black D, Morris JN, Smith C, et al. Inequalities in health: The Black report; The health divide. London: Penguin Group, 1992.

20 Parsons L, Duley L, Alberman E. Socio-economic and ethnic factors in stillbirth and neonatal mortality in NorthEast Thames Regional Health Authority 1983. Br $\mathcal{F}$ Obstet Gynaecol 1990;97:237-44.

21 Olsen J, Frische G. Social differences in reproductive health. A study on birthweight, stillbirths and congenital malforA study on birthweight, stillbirths and congenital mat
mations in Denmark. Scand 7 Soc Med 1993;21:90-7.

22 Xiao OS, Hatch MC, Mills J, et al. Maternal smoking, alcohol drinking, caffeine consumption, and fetal growth: results from a prospective study. Epidemiology 1995;6:11520

23 Berkowitz GS, Papiernik E. Epidemiology of preterm birth. Epidemiol Res 1993;15:414-43.

24 Gibbs RS, Romero R, Hillier SL, et al. A review of premature birth and subclinical infection. Am $\mathcal{F}$ Obstet Gynecol 1992;166:1515-28.

25 Peters A, Doering A, Wichmann HE, et al. Increased plasma viscosity during an air pollution episode: a link to mortality? Lancet 1997;349:1582-7.

26 Zondervan HA, Oosting J, Hardeman MR, et al. The influence of maternal whole blood viscosity on fetal growth. Eur f Obstet Gynecol Reprod Biol 1987;25:187-94.

27 Perera FP, Hemminki K, Gryzbowska E, et al. Molecular and genetic damage in humans from environmental polluand genetic damage in humans from en

28 Petruzzelli S, Celi A, Pulera N, et al . Serum antibodies to benzo(a)pyrene diol epoxide-DNA adducts in the general population: effects of air pollution, tobacco smoking, and family history of lung diseases. Cancer Res 1998;58:4122-6.

29 Topinka J, Binkova B, Mrackova G, et al. Influence of GSTM1 and NAT2 genotypes on placental DNA adducts in an environmentally exposed population. Environ $\mathrm{Mol}$ Mutagen 1997;30:184-95.

30 Perera FP, Whyatt RM, Jedrychowski W, et al. Recent developments in molecular epidemiology: a study of the effects of environmental polycyclic aromatic hydrocarbons on birth outcomes in Poland. Am f Epidemiol 1998;147:30914 . 